\title{
Sudán: ¿islam africano e islam árabe? Dicotomías del islam, el islamismo y el sufismo
}

\author{
Sudan: African Islam and Arab Islam? \\ Dichotomy of Islam, Islam and Sufism
}

\author{
Rafael Ortega ${ }^{1}$ \\ Universidad de Granada (España)
}

Recibido: 20-01-19

Aprobado: 10-03-19

\section{Resumen}

El análisis del islam en Sudán muestra la gran variedad de aproximaciones al objeto de estudio, la diversidad de sus lecturas y el reiterado recurso a los principios religiosos para justificar o legitimar las cuestiones políticas y de Estado. El islam sudanés, en sus diferentes manifestaciones, ha traspasado las fronteras nacionales y ha contribuido al islam africano, árabe y mundial. Eso desde el siglo XIX cuando surgió un primer proto-estado islámico de la mano de esa figura mesiánica que fue Muhammad Ahmad Ibn Abdallah, el Mahdi, hasta el pensador y hombre de Estado Hasan al-Turabi en pleno siglo XX. Analizaremos tres dimensiones: el islam reformista de Mahmud Muhammad Taha, el islamismo sudanés conducido por al-Turabi y el papel del sufismo en la religiosidad popular $\mathrm{y}$ en la política sudanesa, y su reciente confrontación con las tendencias salafíes activas en el país en lo que parece ser una nueva lucha por el espacio socioreligioso del siglo XXI.

Palabras-clave: Sudán, Islam, Reformismo, Islamismo, Salafismo.

\footnotetext{
${ }^{1}$ (rafaelortega@ugr.es) Profesor de Estudios Árabes e Islámicos de la Universidad de Granada. Licenciado en Geografía e Historia por la Universidad de Valencia y Doctor por la Universidad de Granada en Culturas Árabe y Hebrea: lengua, literatura e historia. Sus líneas preferentes de investigación son la historia y el pensamiento del islam político y el islam en España. Su último libro es El movimiento islamista sudanés. Discursos, estrategias y transformaciones. También es traductor jurado y literario del árabe.
} 


\begin{abstract}
The analysis of Islam in Sudan shows the great variety of approaches to the object of study, the diversity of its readings and the repeated recourse to religious principles to justify or legitimize political and State issues. Sudanese Islam, in its different manifestations, has crossed national borders and has contributed to African, Arab and world Islam. This has been like this since the first Islamic proto-state emerged in the Nineteenth century at the hands of the messianic figure who was Muhammad Ahmad Ibn Abdallah, the Mahdi until the thinker and statesman Hasan al-Turabi in the Twentieth century. Three dimensions will be analyzed: the reformist Islam of Mahmud Muhammad Taha, the Sudanese Islamism led by al-Turabi and the role of Sufism in popular religiosity and Sudanese politics, and finally the recent confrontation with the Salafi tendencies active in the country in what seems to be a new struggle for the socio-religious space of the 21 st century.
\end{abstract}

Key-words: Sudan, Islam, Reformism, Islamism, Salafism.

\title{
1. Arabización e islamización de bilad al-sudan
}

Sudán ${ }^{2}$ es un territorio que ha oscilado siempre entre el mundo árabe y el África negra. Esa dicotomía ha marcado su historia y, por lo tanto, sus experiencias del islam, el islamismo, el sufismo, la religión, la política y la configuración del Estado. La arabización e islamización fueron dos fenómenos que no siempre corrieron de la mano. La primera fue consecuencia de un proceso lento iniciado en el siglo VII con las migraciones árabes hacia lo que los geógrafos conocían como "bilad al-sudan", -literalmente "tierra de negros", término que hacía referencia a la amplia zona del África Subsahariana, desde Senegal a Etiopía-, y en dirección a regiones sudanesas como Kordofan (centro), Darfur (oeste), entre las tribus de Nubia (Norte) y la de los Beja (este), por medio de dos fenómenos: las conquistas militares árabes en la zona Nubia del norte (batallas contra los reinos cristianos presentes desde el siglo V) y las relaciones comerciales con los árabes de la Península Arábiga.

La primera arabización e islamización de "bilad al-sudan" fue resultado de un doble proceso: el asentamiento de tribus árabes en la zona oriental, entre el Nilo y el Mar Rojo; y el movimiento comercial que llevó consigo una red de alianzas y una difusión de modelos culturales y religiosos de una civilización

\footnotetext{
${ }^{2}$ Al hablar de Sudán me referiré siempre a la situación anterior a la amputación de Sudán del Sur en 2011, es decir cuando era el país más grande África, con una gran variedad étnica, lingüística, política, religiosa y cultural. Con una extensión de $2.505 .813 \mathrm{~km}^{2}$ y una población de 52.575 .000 habitantes. Tras la separación del sur, el país pasó a tener una extensión de $1.861 .484 \mathrm{~km}^{2} \mathrm{y}$ una población de 40.235.000 habitantes (Véase el mapa adjunto).
} 
considerada más evolucionada que se asentó en la mitad norte del país. Por otro lado, algunos investigadores como Joseph M. Cuoq consideran que la trata de esclavos practicada en la zona favoreció la expansión del islam, ya que "muchos, para escapar de los esclavistas, se declararon musulmanes y a menudo continuaban siéndolo. Pero más grave fue el hecho de que la caza del hombre, al despoblar ciertas regiones y desmantelar las tribus, creó una situación de destribalizados que para encontrar un marco social y cultural con garantías de existencia, no hallaron otra solución que hacerse musulmanes"3.

El proceso de islamización fue más lento $\mathrm{y}$, aunque se había iniciado también de la mano de la arabización, se potenció en épocas más tardías y en varios actos: la conversión de la jefatura Beja y Nubia en el siglo XIV y la labor de las cofradías sufíes. Entre los factores que favorecieron la difusión del islam figuran, igualmente "la doble política seguida por la dinastía africana de los Funj de atraerse, por un lado, a ulemas de la zona de Hiyaz, en los que basaría buena parte de su administración centralizada, y que desempeñarían un papel de intermediarios entre las tribus africanas y árabes y, por otro, de favorecer la apertura de centros de enseñanza religiosa por peregrinos sudaneses instruidos en La Meca, vías por las cuales se introducirán las cofradías sufíes, además de por las influencias procedentes del Magreb Occidental en la zona noroccidental de Sudán"4.

Estos procesos de islamización y arabización se tradujeron en nuevas costumbres, en el uso de la lengua árabe que suplantó progresivamente a los idiomas locales, y en la reivindicación de raíces árabes por parte de la jefatura de algunas tribus que asumieron la cultura árabe e introdujeron el derecho islámico. Este doble proceso se potenció con políticas de alianzas con jefaturas locales, fenómeno al que contribuyó la labor de comerciantes y de instituciones religiosas egipcias como la poderosa al-Azhar.

\subsection{Sufismo e islamización}

Para la islamización fue determinante la labor del sufismo por dos vías: la aparición y llegada de "santones" y la expansión de cofradías sufíes que además desempeñaron un importante papel en la integración social del valle del Nilo sudanés puesto que en su entorno se reunieron individuos procedentes de grupos tribales diferentes. Además, la presencia de santones y cofradías fue potenciada por las jefaturas locales ya que daba prestigio religioso, promovía el desarrollo económico y confería influencia política. Ejemplos de ello se pueden encontrar en la ciudad de Ad Damer (al norte de Jartum) y la cofradía

\footnotetext{
3 Joseph M. Cuoq, Les musulmans en Afrique, Paris, Maisonneuve-Larose, 1975, p. 348.

4 Rafael Ortega Rodrigo, El movimiento islamista sudanés. Discursos, estrategias y transformaciones, Alcalá la Real, Alcalá Grupo Editorial, 2010, p. 21.
}

Araucaria. Revista Iberoamericana de Filosofia, Política, Humanidades y Relaciones Internacionales, año $21, \mathrm{n}^{\circ} 41$. Primer semestre de 2019. Pp. 439-464. ISSN 1575-6823 e-ISSN 2340-2199 doi: 10.12795/araucaria.2019.i41.21 
sufí Madjdubiyya en épocas más recientes (principios del siglo XIX)5. Pero la llegada de las primeras cofradías sufíes a territorio sudanés se produjo en el siglo XVI, cuando el sultanato africano de los Funj, recientemente islamizado, solicitó a Egipto ${ }^{6}$ y a la zona del Hiyaz (península Arábiga), el envío de ulemas. Así fue como comenzó a difundirse por el territorio la tariqa Qadiriyya, fundada por el bagdadí 'Abd al-Qadir al-Yilani (m. 1166), considerada la más extendida en el mundo islámico. Tenemos que señalar que las cofradías sufíes llevaron a cabo una importante labor educativa a través de sus escuelas. Un segundo momento de gran presencia sufí se produjo en el siglo XIX cuando llegaron las ideas reformistas sufíes de la península Arábiga y se fundaron nuevas cofradías, entre ellas las dos más importantes en la historia de Sudán: la Jatmiyya (también denominada Mirganiyya), fundada en la primera mitad del siglo XIX por el mequí Muhammad Uzman al-Mirgani (1792-1853), con una fuerte implantación en el norte y este del país; y la Mahdiyya (o al-Ansar) fundada en la segunda mitad del siglo XIX por al-Sayyid 'Abd al-Rahman al-Mahdi (1885-1959), presente sobre todo en el oeste y centro de Sudán y expresión del sufismo puramente sudanés ${ }^{7}$. Ambas contribuyeron a profundizar la islamización de la sociedad sudanesa y de ellas surgieron los principales partidos que han dominado la vida política local hasta la llegada del islamismo al poder en 1989, nos referimos al Partido al-Umma, estructurado en torno a la tariqa Mahdiyya, y al Partido Unionista Nacional y el Partido Democrático del Pueblo apoyados en la Jatmiyya. Así se produjo la confluencia entre el poder espiritual del que disfrutaban los maestros sufíes, el poder económico -ya que la jefatura de las cofradías estaba formada por grandes terratenientesy el poder político en la época inmediatamente anterior a la independencia sudanesa en 1956.

Es decir, el islam se introdujo en Sudán de la mano de los sufíes, de forma alternativa a la vía de las campañas militares fracasadas dirigidas por el gobernador del Alto Egipto en el siglo VII bajo el califato de Uzmán. El activismo de las cofradías sufíes ayudó a difundir el llamamiento del islam (creación de escuelas coránicas llamadas jalawa en Sudán, mezquitas, centros académicos), hasta el punto de que los sufíes crearían un sultanato islámico, el de Sennar (1504-1821). Las tariqas se involucraron en la revolución del Mahdi

\footnotetext{
${ }^{5}$ Véase Nicole Grandin, "El noreste y el este de África", [en Alexandre Popovic y Gilles Veisntein, eds.: Las sendas de Allah. Las cofradías musulmanas desde sus origenes hasta la actualidad, Barcelona, Bellaterra, 1997], pp. 527-543.

${ }^{6}$ La historia de Sudán ha estado siempre muy vinculada a la de Egipto, tanto en la difusión del islam como en el surgimiento del islamismo, en la formación de los partidos políticos o, incluso, en el colonialismo. Egipto siempre ha querido ejercer de "tutor" de su vecino del sur. Por ejemplo, el poder político y la influyente institución religiosa egipcia de al-Azhar justificaron el colonialismo egipciootomano en Sudán como labor "civilizadora" frente a las tribus "salvajes" del país.

7 Véase Rafael Ortega Rodrigo. El movimiento islamista sudanés. Discursos, estrategias y transformaciones. Alcalá la Real: Alcalá Grupo Editorial, 2010, pp. 23-24.
} 
que acabó con el colonialismo egipcio-otomano (1821-1885); los "derviches", es decir los sufíes, lucharon contra la potencia británica que acabó con el Estado mahdista en 1899; contribuyeron al proceso que conduciría a la independencia del país a través de pequeñas revoluciones, como la Abdelqader Wad Habuba (1908); y después apoyaron a los dirigentes de los primeros partidos políticos hasta la salida de los ingleses en 1956. Podemos considerar el sufismo en Sudán como un elemento de continuismo desde la entrada de las primeras cofradías al mismo tiempo que han cumplido también una función de "colchón" ante una posible mayor expansión del islam político.

\subsection{La revolución de al-mahdi y la islamización}

Otro de los factores que indudablemente contribuyó a la islamización de parte de Sudán fue la revolución de al-Mahdi (finales del siglo XIX): una combinación de objetivos políticos y religiosos con una dimensión nacionalistarevolucionaria y otra mesiánica-profética que, entre otros objetivos, pretendía acabar con la división de las cofradías y las creencias paganas, pero que bajo esa apariencia religiosa "tenía claramente objetivos sociales y políticos" el movimiento mahdista confluyeron el surgimiento de un líder carismático, Muhammad Ahmad Ibn Abdallah (1844-1885) que asumió el papel de mahdi; el rechazo a la autoridad establecida, en este caso la dominación egipcio-otomana; el recurso a las masas; un mensaje universalista; la creación de una forma organizativa más o menos estable; un código de vida personal impregnado de "puritanismo" (emanado de la obra Ratib al-Imam al-Mahdi, compendio de sermones e instrucciones de al-Mahdi); y las múltiples crisis?.

Para el islam sunní, en momentos de crisis religiosa y política debía surgir un descendiente del Profeta, anunciador del final de los tiempos, que desempeñaría el papel de mahdi (literalmente "el guiado por Dios") cuyas misiones serían: gobernar con justicia y equidad, reorganizar el Estado y purificar la religión. Según la creencia popular sudanesa, el Mahdi debía aparecer a finales de siglo XIII de la hégira, es decir en los años ochenta del siglo XIX, para restablecer la pureza del islam. En 1881, Muhammad Ahmad Ibn Abdallah, autoproclamado al-Mahdi, se alzó contra la expansión colonial de la administración egipcia del jedive Ismail (1863-1879), que pretendía "modernizar" Sudán y acabar con la trata de esclavos. La expansión egipcia fue uno más en el cúmulo de factores que provocaron la crisis de la sociedad tradicional sudanesa, y a ésta se tienen que añadir: la creación de un sistema administrativo centralizado con nuevas cargas fiscales gestionado por funcionarios egipcios enviados a Sudán; la progresiva sustitución de los alfaquíes locales por ulemas egipcios; los intentos

\footnotetext{
${ }^{8}$ P. M. Holt, "al-Mahdiyya”, Encyclopédie de l'Islam, $2^{\mathrm{a}}$ ed., vol V, p. 1238.

9 Thomas Hodgkin, "Mahdismo, mesianismo y marxismo en el continente africano", [en El empuje del islam, África Internacional, $\mathrm{n}^{\circ}$ 7, 1988], p. 10.
}

Araucaria. Revista Iberoamericana de Filosofia, Política, Humanidades y Relaciones Internacionales, año $21, \mathrm{n}^{\circ} 41$ Primer semestre de 2019. Pp. 439-464. ISSN 1575-6823 e-ISSN 2340-2199 doi: 10.12795/araucaria.2019.i41.21 
de acabar con el comercio de esclavos, que suponían un ataque directo a los derechos adquiridos por algunas tribus dedicadas al comercio de esclavos; y el reclutamiento por parte del jedive egipcio de mercenarios y militares europeos cristianos, que le confería una nueva dimensión religiosa a la crisis social. Pero también se produjo una crisis demográfica y económica debida a las migraciones por motivos económicos de tribus del norte hacia el sur, lo que provocó una ruptura de la cohesión tribal, una crisis social debida a la urbanización acelerada y a la atrofia de la autoridad tradicional de los jefes de tribu, que les llevaría a colaborar con el enemigo para mantener su estatus, como el caso de la familia al-Mirgani. A estas tensiones hay que añadir la reacción contra la ortodoxia institucional del islam azharí impuesta por la nueva administración que suponía una confrontación con la autoridad tradicional político-religiosa y el papel de los alfaquíes frente a los ulemas importados de Egipto. Esta confluencia de factores facilitó la emergencia del concepto de $\operatorname{mahdi}^{10}$.

Abdallah, ya con el título de "califa", fue el sucesor de al-Mahdi, y logró poner en pie una administración propia entre 1885 y 1898, un Estado cohesionado que contó con el apoyo de los sectores más oprimidos, de los sufíes que consideraban el islam representado por la administración egipciootomana como algo degenerado, la clase media para la cual la trata de esclavos representaba su modus vivendi; tribus nómadas que sufrían las presiones de la nueva política fiscal de la administración colonial; y todos aquellos que creían necesaria una purificación del islam de costumbres ajenas. Esa primera experiencia de protoestado nacional sudanés desapareció debido, fundamentalmente, a la intervención militar británica en plena carrera colonialista europea. Fue la primera reivindicación del islam como conjunto de principios reguladores del ámbito político y social y como elemento cohesionador frente a amenazas exteriores que se podría contextualizar en los movimientos mahdistas surgidos en lo que se conocía como "bilad al-sudan".

Pero el movimiento mahdista también se inspiró en factores exógenos, principalmente en la figura de Uzman dan Fodio (1754-1817), promotor de la islamización de la zona Nigeria-Níger-Chad, y del África Occidental en general, a través de la creación del califato de Sokoto y de su movimiento yihadí-reformista contra las autoridades de la etnia dominante, los Hausas, que practicaban un sincretismo entre islam y creencias animistas.

La experiencia mahdista ha permanecido en la memoria histórica del pueblo sudanés y ha sido utilizada por diferentes actores a lo largo del siglo XX. Los gobiernos tras la independencia del país buscaban legitimidad en aquella experiencia nacionalista: el presidente Numeyri (1969-1985) explicó su transición desde posturas nacionalistas e izquierdistas a la islamización del

10 Rafael Ortega Rodrigo, El movimiento islamista sudanés. Discursos, estrategias y transformaciones. Alcalá la Real: Alcalá Grupo Editorial, 2010, pp. 26-27.

Araucaria. Revista Iberoamericana de Filosofia, Política, Humanidades y Relaciones Internacionales, año $21, \mathrm{n}^{\circ} 41$. Primer semestre de 2019. Pp. 439-464. ISSN 1575-6823 e-ISSN 2340-2199 doi: 10.12795/araucaria.2019.i41.21 
Estado recurriendo a la memoria de la experiencia mahdista; el actual presidente al-Bashir (1989-) vinculó la "revolución de salvación” que lideró en 1989 (un golpe de Estado islamista contra el gobierno elegido democráticamente) con la revolución mahdista. Incluso tuvo sus repercusiones fuera de las fronteras sudanesas tal y como señalaremos más adelante.

Según la investigadora Ann Mosely Lesch, a finales del pasado siglo XX, todavía en medio de la larga guerra civil sudanesa, los nacionalistas del norte veían la experiencia mahdista como la clave del "movimiento de liberación nacional" que había unificado el país en una única nación, trascendiendo las alianzas tribales y sectarias. En el sur la visión era diferente, si bien algunos habitantes de esa zona habían colaborado con al-Mahdi para expulsar a las tropas egipcias, después se rebelarían contra su Estado cuando éste comenzó a imponer un gobierno centralizado, a aplicar una política fiscal impositiva y a reanudar el comercio de esclavos. La Mahdiyya es reconstruida en el imaginario nacional del norte como un periodo de liberación y de afirmación de los valores culturales, como una edad de oro, pero en el sur es vista como la culminación de las depredaciones de la "turkiyya", la época de control egipciootomano sobre Sudán ${ }^{11}$.

\section{Política y religión}

Política y religión han ido de la mano en la conformación del Sudán moderno, desde las primeras fórmulas de gobierno independiente. Ya inmediatamente después de la independencia se planteó el debate nacional sobre la elaboración de una constitución representativa de la sociedad y las fuerzas sudanesas y de un sistema jurídico ${ }^{12}$. Desde ese momento, hay voces en el país que reivindican una constitución islámica y un sistema jurídico que incluya tanto el derecho consuetudinario como la ley islámica, la sharia, y desde entonces ambas cuestiones se harán recurrentes en la historia sudanesa. Estos debates fueron interrumpidos con el primer golpe de Estado, dirigido por el general Ibrahim Abbud en 1958. Un nuevo régimen de corte nacionalista se instauró en Jartum, apoyado por la cofradía sufí Jatmiyya, que desplegó una campaña de arabización e islamización de las provincias del sur ${ }^{13}$. De hecho,

11 Ann Mosely Lesch, The Sudan. Contested ational Identities, Bloomington-Oxford, Indiana University Press y James Currey Ltd., 1998, p. 28.

12 El colonialismo británico de Sudán (1898-1955) consolidó la separación entre el norte (en general árabe e islámico) y el sur (mayoritariamente poblado por tribus negras cristianas o animistas) e impuso una administración especial sobre las provincias meridionales que las aisló y las mantuvo al margen de los procesos hacia la independencia que se estaban fraguando básicamente en el norte. Fue el germen de la larga guerra civil del país (1955-2005).

${ }_{13}$ Robert O. Collins, A History of Modern Sudan, New York, Cambridge University Press, 2008, p. 79. La historia política de Sudán es una sucesión de breves períodos “democráticos” (1956-1958;

Araucaria. Revista Iberoamericana de Filosofia, Politica, Humanidades y Relaciones Internacionales, año $21, \mathrm{n}^{\circ} 41$. Primer semestre de 2019. Pp. 439-464. ISSN 1575-6823 e-ISSN 2340-2199 doi: 10.12795/araucaria.2019.i41.21 
la Constitución fue anulada y los partidos ilegalizados, incluidos los islamistas Hermanos Musulmanes de Sudán y Frente Islámico de la Constitución. En la siguiente etapa tras la revuelta popular que acabó con el régimen de Abbud asistimos a la lucha por el espacio político entre el Partido Comunista Sudanés y el movimiento islamista activo bajo el paraguas del Frente de la Carta Islámica. Así, el movimiento islamista comenzó a crear uniones profesionales alternativas a los sindicatos existentes controlados por el Partido Comunista, presionó sobre el gobierno formado tras las elecciones de 1965 (controlado por los grandes partidos basados en cofradías sufíes) e inició una dura campaña en los medios, en el parlamento y desde las mezquitas con el objetivo de que el gobierno ilegalizara al Partido Comunista y expulsara a sus miembros del parlamento, objetivo conseguido un año después. En este nuevo período "democrático" se retomó el debate de la elaboración de una Constitución en el que las fuerzas islamistas volvieron a defender la Constitución islámica en una comisión que redactó un borrador de constitución. Ese borrador reconocía el islam como la religión oficial del Estado - con lo que ello significaba en un país con unas importantes minorías cristiana y animista-, la shura (la práctica islámica basada en la consulta entre aquellos capacitados para ello) como la base del sistema de gobierno, la sharia sería la principal fuente del derecho, el árabe la lengua oficial y que el país formaría parte de las entidades árabe, islámica y africana. Sin embargo, los avances producidos en este terreno fueron cortados por el golpe de Estado dirigido por el coronel Yaafar Numeyri en mayo de 1969 de tendencia, inicialmente, comunista y que contaba con los apoyos de partidos políticos del sur, fuerzas laicas, izquierdistas y el Partido Republicano de Mahmud Muhammad Taha. Sin embargo, el régimen de Numeyri que partía de posturas izquierdistas nacionalistas contrarias al islam y al islamismo, se encaminó hacia una progresiva islamización que culminó en la promulgación de las leyes de septiembre de 1983, supuestamente una legislación islámica, y en su autoproclamación como imam de los creyentes.

Vamos a detenernos en dos cuestiones que son buen ejemplo de la islamización, del recurso al islam y a la religiosidad por parte del régimen de Numeyri: el acercamiento a las pequeñas cofradías sufíes y las leyes de septiembre de 1983 promulgadas por el régimen de Numeyri, leyes represivas revestidas de sharia.

En un panorama normalmente dominado por las grandes tariqas, Jatmiyya y Mahdiyya, las nuevas autoridades de Jartum, en principio contrarias a cualquier elemento religioso que consideraban como una rémora para el progreso, se fueron distanciando de las fuerzas de izquierda que habían recurrido a intentonas golpistas contra el régimen de Numeyri, y comenzaron

1964-1969; 1985-1989) y de largos regímenes militares resultado de golpes de Estado (1958-1964; 1969-1985; 1989-)

Araucaria. Revista Iberoamericana de Filosofía, Política, Humanidades y Relaciones Internacionales, año $21, \mathrm{n}^{\circ} 41$. Primer semestre de 2019. Pp. 439-464. ISSN 1575-6823 e-ISSN 2340-2199 doi: 10.12795/araucaria.2019.i41.21 
un acercamiento a cofradías menores como la Qadiriyya, Maydubiyya, Sammaniyya e Ismailiyya, con el fin de marginar a las grandes y también a sus respectivos partidos, especialmente tras la represión de la oposición armada de la tariqa al-Ansar en el feudo de la familia al-Mahdi, la isla de Aba (situada en el Nilo Blanco, al sur de Jartum), en 1970. ¿Cómo se produjo ese acercamiento? En primer lugar nombrando en puestos de dirección a personalidades de reconocido prestigio sufí o relacionadas con las tariqas ${ }^{14}$, ayudando económicamente a las celebraciones religiosas, e incluso haciendo visible ese apoyo del régimen con visitas del presidente Numeyri a las tariqas. Al final de este proceso, estas cofradías sufíes menores se integraron en el partido único creado por el presidente, la Unión Socialista Sudanesa. Pero las muestras de "islamización" del régimen fueron muchas y variadas: lanzamiento del proyecto de "revitalización del espíritu de la religión" y regreso al seno del islam (con la creación del Organismo de Revitalización de la Actividad Islámica); promoción de la construcción de mezquitas y escuelas religiosas, apoyo a las ya existentes, concursos de memorización del Corán, creación del ministerio de Asuntos Religiosos y Bienes Píos, el proyecto de "mezquita total" (destinada tanto al culto como a actividades sociales)... Numeyri pretendía convertirse en el guía religioso del país y las directrices que adoptó en esta dirección establecían paralelismos con la vida del Profeta. Esa serie de directrices y ejemplos se conoció en Sudán como "la jefatura ortodoxa" (alqiyada al-rashida): el buen dirigente musulmán, a imitación del propio Jefe de Estado que se presenta a sí mismo como el modelo de hombre piadoso a imitar, debe ser capaz de vencer sus propias pasiones o de lo contrario presentar su dimisión, es decir, alejarse de vicios y defectos, como el consumo de bebidas alcohólicas, y en el caso de que no pueda es que no es digno de tener un cargo dirigente; además, ese compromiso debe hacerlo por escrito en respuesta a la carta del Presidente ${ }^{15}$. Así pues, el viaje del presidente Numeyri desde su acceso al poder aupado por las fuerzas de izquierda hasta su autodesignación como "príncipe de los creyentes" estuvo jalonado de actos, decisiones y políticas de islamización que buscaban, al mismo tiempo, la reconciliación con las fuerzas islamistas y las cofradías sufíes, ya que necesitaba su apoyo para seguir en el poder: imágenes de Numeyri en la peregrinación, declaraciones presidenciales sobre el islam como corazón de la Constitución, islamización de los planes de estudio, disolución de organismos de apuestas, limitación del consumo de alcohol, y recreación de una hagiografía de Numeyri en la que se destacaba su religiosidad.

14 Idris Salim al-Hasan, al-Din fi-l-muytamaa al-sudani. Numayri wa-l-turuq al-sufiyya (La religión en la sociedad sudanesa. Numeyri y las cofradías sufíes), El Cairo: Markaz al-Dirasat alSudaniyya, 2002, p.89

15 Muhamad Said al-Qaddal, al-Islam wa-l-siyasa fi-l-Sudan, 1651-1985, Beirut, Dar al-Yil, 1992, p. 178.

Araucaria. Revista Iberoamericana de Filosofia, Política, Humanidades y Relaciones Internacionales, año $21, \mathrm{n}^{\circ} 41$. Primer semestre de 2019. Pp. 439-464. ISSN 1575-6823 e-ISSN 2340-2199 doi: 10.12795/araucaria.2019.i41.21 
Por otro lado, para demostrar su religiosidad y atraerse definitivamente a las fuerzas islamistas, el régimen emprendió una campaña de, presuntamente, islamización de la legislación, cumpliendo su promesa electoral de 1977 cuando resultó reelegido tras la reconciliación con las fuerzas del islam político. Tras su reelección, el régimen introdujo una serie de enmiendas en virtud de las cuales la sharia pasaría a ser la fuente principal de la legislación. Desde entonces y hasta 1983, una serie de comisiones controladas por el régimen en las que entran y salen dirigentes islamistas, entre ellos el sheyj Hasan al-Turabi, elaboraron propuestas para revisar la legislación e islamizarla: prohibición de bebidas alcohólicas, del juego, la usura y control de la moral pública. Este proceso de revisión de la legislación concluyó en septiembre de 1983 con la "proclamación de la sharia" como ley del Estado. Ahora bien, esta actuación del régimen sigue generando controversia ya que para algunos historiadores, como Gérard Prunier, las leyes de septiembre, como son conocidas, eran leyes represivas más que islámicas y "tenían un carácter laico autoritario dirigido a la represión de los delitos de opinión"16, que en virtud de esa nueva legislación "islámica" se convertían en delitos de apostasía, y permitían al régimen recurrir a las sanciones coránicas, los castigos corporales (hudud). El recurso a este tipo de castigos contemplados en el nuevo código penal confirmaba ante la opinión pública islámica que el régimen, efectivamente, era islámico y gobernaba con la legislación revelada por Dios, de manera que con tal argumentación anulaba, teóricamente, cualquier oposición procedente de las filas de los islamistas y los círculos religiosos conservadores. Además, y bajo el paraguas de la sharia, el régimen de Numeyri recurrió a otro principio islámico, la hisba: la promoción de la virtud y la prevención del vicio, un deber de cualquier buen musulmán que aparece mencionado en El Corán y que hace que el individuo se involucre en la aplicación de la sharia ${ }^{17}$. Así, en el Sudán de Numeyri posterior a las leyes de septiembre surgieron grupos dedicados al control de la moral pública a través de este principio de la hisba. Tales grupos fueron creados por decreto presidencial bajo la supervisión del Consejo Superior de Asuntos Religiosos y estaban coordinados por una especie de guía censor ${ }^{18}$.

El autoritarismo del régimen, la reanudación de la guerra civil en 1983 debido a una reordenación administrativa que adscribía las provincias meridionales

${ }^{16}$ Gérard Prunier, "Les Fréres musulmans au Soudan: un islamisme tacticien" [en Marc Lavergne, ed. : Le Soudan contemporain. De l'invasion turco-égyptienne à la rèbellion africaine (1821-1989), Paris-Amman: Karthala-Cermoc, 1989], pp. 359-380, esp. p. 369.

${ }^{17}$ Como señala Bahige Mulla Huech, la hisba es el "control popular de la buena aplicación de la ley". En Bahige Mulla Huech, Diccionario del Sagrado Corán, Barcelona, Consestruc, 2013, p. 210. Este principio aparece en las azoras coránicas La Familia de 'Imrán (aleyas 194 y 110), el Arrepentimiento (aleya 71), la Peregrinación (aleya 41) y Luqmán (aleya 17); así como también en varios hadices del Profeta.

${ }_{18}$ Véase Hasan Makki, al-Haraka al-islamiyya fi-l-Sudan (1969-1985). Tariju-ha wa-jitabu-ha l-siyasi, Jartum, al-Dar al-Sudaniyya li-1-Kutub, 1999, p.171.

Araucaria. Revista Iberoamericana de Filosofia, Política, Humanidades y Relaciones Internacionales, año $21, \mathrm{n}^{\circ} 41$ Primer semestre de 2019. Pp. 439-464. ISSN 1575-6823 e-ISSN 2340-2199 doi: 10.12795/araucaria.2019.i41.21 
con recursos petrolíferos directamente al gobierno central (lo que suponía el incumplimiento de los acuerdos de paz de Addis Abeba firmados en 1972), el aislamiento interno y en la escena internacional, la política económica errática, la ejecución del intelectual y político Mahmud Muhammad Taha, provocaron el levantamiento popular y el golpe de Estado de abril de 1985 que acabó con el régimen de Numeyri e inauguró la tercera experiencia parlamentaria sudanesa que duró poco, tan solo hasta junio de 1989. Durante este nuevo periodo democrático, caracterizado por gobiernos de coalición en los que cada vez adquirirá más protagonismo el movimiento islamista dirigido por el sheyj Hasan al-Turabi, el Frente Islámico Nacional (FIN), se comenzó a borrar el legado de Numeyri, en primer lugar la derogación de las leyes de septiembre, la prohibición de los castigos corporales, y la inclusión del derecho consuetudinario como fuente de la legislación junto con la sharia, entre otras medidas adoptadas por los sucesivos gobiernos formados por los partidos mayoritarios al-Umma (de la tariqa al-Ansar o Mahdiyya) y el Unionista Democrático (de la Jatmiyya o Merganiyy), junto con el recién creado FIN, resultado de la evolución del islamismo liderado por al-Turabi, que entraba y salía de los diferentes gobiernos de coalición. Hasta que el FIN, de la mano de un grupo de militares islamistas encabezados por el oficial Omar Hasan al-Bashir, dio el golpe de Estado de 1989 y se constituyó un régimen islamista, el primero en el mundo árabe, que con numerosas evoluciones y cambios permanece hasta nuestros días.

\section{La larga marcha del islamismo sudanés}

El islam político sudanés surgió en una sociedad mayoritariamente islamizada y arabizada, exceptuando las provincias al sur del paralelo $10^{\circ}$ que habían sido sometidas a una administración especial bajo el colonialismo británico que las aislaba de las provincias arabizadas e islamizadas del norte y del centro. Como en otros muchos aspectos, la influencia egipcia fue decisiva para la formación del primer grupo islamista en Sudán, los Hermanos Musulmanes de Sudán, en 1944, en época del condominio anglo-egipcio. Sin embargo, el islamismo sudanés tuvo desde épocas tempranas una dimensión africana e internacional puesta de manifiesto en el discurso parlamentario del sheij Hasan al-Turabi, en 1965: "Pertenecemos a África y en concreto al África central musulmana, así pues debemos apoyar las diferentes causas de África como Mozambique, Angola y el Congo, y ayudar a las causas de los pueblos que nos rodean de manera especial. También pertenecemos a los países árabes, en virtud de la religión, la lengua y la historia, y tenemos que defender las cuestiones de los árabes en Palestina y en el sur de la Península Arábiga. Y también pertenecemos a la Comunidad Islámica y nos 
preocupamos por las cuestiones de los países islámicos como el problema de Cachemira o el de los musulmanes de Asia Central"19.

Si bien el islamismo sudanés surgió como prolongación del movimiento aparecido en Egipto en la década de los veinte del pasado siglo, los Hermanos Musulmanes, rápidamente hizo frente a un debate interno en Sudán sobre su identidad y su relación con la organización madre. Progresivamente surgieron dos tendencias principales: la que reconocía su dependencia del islamismo egipcio y la que defendía la especificidad sudanesa. Ambas han convivido desde mediados del siglo XX hasta hoy en día: por un lado se mantiene el grupo de los Hermanos Musulmanes de Sudán, fuertemente vinculado con los Hermanos Musulmanes de Egipto, y por otro la tendencia propiamente sudanesa que pasó por experiencias muy diferentes, dando lugar a formaciones que se han ido sucediendo a lo largo de las pasadas décadas, y que siempre ha estado dirigida y guiada por el sheyj Hasan al-Turabi (1932-2016), pensador, hombre de Estado y personaje mediático. Él fue el artífice de la evolución del movimiento islamista, el teórico del "proyecto civilizacional" del movimiento y de su llegada al poder en 1989 a través del golpe de Estado. Impulsó las dos dimensiones del movimiento: la interna con el objetivo de la islamización gradual y total de la sociedad y la externa con la creación de la Conferencia Popular Árabe e Islámica en 1992, como foro internacional en Jartum para todos los movimientos islamistas (tolerados o prohibidos en sus respectivos países) y alternativa a la Organización Internacional de los Hermanos Musulmanes. La CPAI fue también un foro de debate entre musulmanes, islamistas, izquierdistas, comunidades de conversos procedentes de Europa o América Latina, representantes suníes y shí́es y cristianos que tuvo una vida corta (de abril de 1991 a abril de 1995). Sus objetivos fueron básicamente "ofrecer resistencia a los intentos estadounidenses de imponer un nuevo orden mundial y curar las heridas que había dejado en la Umma, en la Comunidad Musulmana, la guerra del Golfo" 20 , y el hecho de que un país árabe (Iraq) hubiera invadido a un país hermano (Kuwait).

Por lo que se refiere a la dimensión interna, el islamismo sudanés de alTurabi tomó diferentes formas a lo largo de las últimas décadas: el Frente Islámico de la Constitución (alianza coyuntural de organizaciones políticas, religiosas y culturales) en los años 50 del pasado siglo en unos momentos en los que el debate público giraba en torno a la elaboración de una Constitución que, obviamente, para el islamismo debía ser una Constitución islámica que debía ir acompañada de la islamización del sistema judicial, lo cual podemos considerar como el primer intento de recurrir a la religión para una finalidad política; tras

${ }^{19}$ Hasan Makki, Harakat al-Ijwan al-Muslimin fi-l-Sudan 1944-1969, Kuwait, Dar al-Qalam li-1Nashr wa-1-Tawzii, 1986, págs. 111-112.

${ }^{20}$ Rafael Ortega Rodrigo, El islam politico en Sudán. Una propuesta fallida de internacional islamista, Granada: Editorial Universidad de Granada, 2004, p. 9.

Araucaria. Revista Iberoamericana de Filosofia, Política, Humanidades y Relaciones Internacionales, año $21, \mathrm{n}^{\circ} 41$ Primer semestre de 2019. Pp. 439-464. ISSN 1575-6823 e-ISSN 2340-2199 doi: 10.12795/araucaria.2019.i41.21 
el golpe de Estado del general Ibrahim Abbud, el islamismo sudanés sufrió una primera etapa de represión hasta el levantamiento popular de octubre de 1964 que acabó con el régimen de Abbud y en ese nuevo periodo "democrático", el islamismo tomó otra forma, el Frente de la Carta Islámica, dirigido por al-Turabi, inmerso de nuevo en el debate sobre la Constitución islámica y la lucha de influencia contra el Partido Comunista -al que acabó expulsando del parlamento y provocó su ilegalización- en diferentes ámbitos, especialmente en los sindicatos y las uniones de estudiantes. Ese periodo parlamentario fue muy breve y concluyó en mayo de 1969 con el golpe de Estado del coronel Yaafar al-Numeyri en un principio de tendencia comunista que ilegalizó al movimiento islamista y detuvo a sus dirigentes. Esto provocó una radicalización que hizo que el movimiento islamista participara en la resistencia armada de la mano de la tariqa sufí de al-Ansar contra el nuevo régimen golpista. Como hemos señalado anteriormente, el régimen de Mayo nació con una orientación marxista pero tal orientación duró poco ya que en 1971 y tras un intento de golpe de Estado protagonizado por dirigentes comunistas, el régimen comenzó a orientarse hacia una progresiva islamización buscando apoyos entre las filas de los islamistas y las cofradías sufíes. El camino del nuevo régimen de Mayo estuvo sembrado de intentonas golpistas fallidas en las que participaron también dirigentes islamistas junto con el resto de partidos que habían sido ilegalizado y excluidos de la vida política (al-Umma, Nacional Unionista). Pero al mismo tiempo, las manifestaciones de religiosidad del régimen fueron haciéndose más claras y numerosas, hasta que se desembocó en la reconciliación nacional con el islamismo de al-Turabi. Esta reconciliación tuvo como resultado el acceso de dirigentes islamistas a puestos de poder, entre ellos al-Turabi (que llegó a ser ministro de Justicia entre 1979 y 1983), el ingreso del movimiento en el partido único creado por Numeyri, la Unión Socialista Sudanesa, y el incremento de la presión para islamizar la sociedad, especialmente la legislación y la economía ${ }^{21}$ (de hecho, el primer banco islámico en Sudán, el Banco Faysal, abrió sus puertas en mayo de 1977, dos meses antes de la reconciliación).

Esta nueva situación en el país dio alas al movimiento islamista liderado por al-Turabi quien comenzó una política exterior dirigida hacia la República Islámica de Pakistán (las autoridades pakistaníes invitaron a al-Turabi a participar en la elaboración de la legislación del país) y la nueva jefatura iraní tras la revolución que acabó con el régimen del Shah Mohammad Reza Pahleví. Al mismo tiempo, creó en 1980 la Organización de Predicación (Daawa) Islámica, un mecanismo de difusión del ideario del islamismo sudanés y de

\footnotetext{
${ }^{21}$ Según señala Hasan al-Turabi, la represión ejercida por el régimen de Numeyri en sus primeros años contra el movimiento islamista obligó a miembros del grupo a refugiarse en actividades económicas dentro y fuera del país, lo cual constituyó una importante base social para la economía islámica y el surgimiento de una nueva burguesía islamista en el país. Hasan al-Turabi, al-Haraka alislamiyya fi-l-Sudan. Al-Tatawwur, al-kasb, al-minhay, Jartum: s.e., 1989, p. 33.
}

Araucaria. Revista Iberoamericana de Filosofia, Politica, Humanidades y Relaciones Internacionales, año $21, \mathrm{n}^{\circ} 41$. Primer semestre de 2019. Pp. 439-464. ISSN 1575-6823 e-ISSN 2340-2199 doi: 10.12795/araucaria.2019.i41.21 
la islamización social activa en las provincias del sur del país con el fin de atraer a esas provincias meridionales al proyecto islámico de Turabi, y llevar la predicación, la acción social y las obras benéficas a zonas no musulmanas de países africanos ${ }^{22}$. Las provincias del sur fueron un destino de la daawa islámica e islamista del régimen desde 1989, en cierta manera las provincias del sur también tenían una presencia minoritaria del islam, del movimiento islamista y de las cofradías sufíes, frente al cristianismo y el animismo mayoritarios.

También en la dimensión interna, pocos años después de la reconciliación Numeyri-movimiento islamista y ante el progresivo ascenso de este último, Numeyri volvió a cambiar de orientación y en pleno proceso de decadencia (reanudación de la guerra civil, ejecución del pensador Mahmud Muhammad Taha, pérdida de apoyos internos e internacionales), se produjo una nueva ruptura entre ambas partes poco antes del levantamiento popular de abril de 1985 que acabó con el régimen de Numeyri. Poco después del levantamiento y de nuevo rehabilitado tras haber pasado por las cárceles del viejo régimen, alTurabi fundó el Frente Islámico Nacional (FIN), penúltima etapa en su periplo de líder del islamismo sudanés y líder en ciernes del islamismo internacional, de hecho el FIN se autodefine como parte integrante de un fenómeno global, el "despertar islámico" (al-sahwa al-islamiyya) que había empezado a producirse pocos años antes en la Comunidad Islámica, la Umma. Desde la tribuna del FIN, al-Turabi formuló su "proyecto civilizacional" holístico, de islamización total y progresiva de la sociedad sudanesa.

La política del FIN en el plano interno sudanés se focalizó en la sharia como mecanismo fundamental para conseguir el objetivo de la islamización total de la sociedad y las instituciones. (No hay que olvidar que el líder y teórico del islamismo sudanés, al-Turabi, era licenciado en Derecho Islámico y había ampliado estudios tanto en Londres como en París, sobre Derecho Positivo y Derecho Comparado). Para el FIN, y por lo tanto para el propio al-Turabi, la sharia no se limita al Derecho Islámico (Fiqh) "sino que es un modelo de vida con principios doctrinales y de acción de los que emanan leyes, enseñanzas, una moral y un modelo de sociedad virtuosa" ${ }^{23}$, una visión alejada de la propuesta reduccionista de la sharia contemplada en las leyes de septiembre de 1983 promulgadas por el régimen de Numeyri.

El fructífero periodo de teorización emprendido por el islamismo sudanés durante esta tercera experiencia parlamentaria de 1985 a 1989, se plasmó en varios documentos fundamentales que años después, tras el golpe de Estado

\footnotetext{
22 Aunque su sede central está en Jartum, la organización cuenta en la actualidad con oficinas en Qatar, Bahrein, Emiratos Árabes Unidos y Yemen y despliega su actividad en numerosos países africanos. Véase: http://www.aljazeera.net/encyclopedia/organizationsandstructures/2016/6/16/\%D9 \%85\%D9\%86\%D8\%B8\%D9\%85\%D8\%A9-\%D8\%A7\%D9\%84\%D8\%AF\%D8\%B9\%D9\%88\%D8 \%A9-\%D8\%A7\%D9\%84\%D8\%A5\%D8\%B3\%D9\%84\%D8\%A7\%D9\%85\%D9\%8A\%D8\%A9

${ }^{23}$ Hasan al-Turabi, Risalat al-Muutamar al-Thani, Jartum, al-Muhammadiyya, s.d., p. 15.
} 
de 1989, los islamistas intentaron traducir a la realidad. Documentos como la Risalat al-Muutamar al-Thani (Epístola del Segundo Congreso), la Sudan Charter: National Unity and Diversity (Carta de Sudán: Unidad Nacional y Diversidad) (1987), el libro de al-Turabi al-Haraka al-Islamiyya fi-l-Sudan. AlTatawwur, al-Kasb, al-Minhay (El movimiento islámico en Sudán. Evolución. Logros. Método) (1989), plasmaron la historia, la ideología y las estrategias del islamismo liderado por al-Turabi, y en ellos se observa la fusión entre religión y Estado y la necesidad de la presencia de la primera en todas las actividades del ser humano encargándose el Estado y sus instituciones de ello. "La Constitución islámica, el Estado y la religión son uno", llegó a decir al-Turabi ${ }^{24}$.

A partir de 1990 se inició el proceso de islamización total teorizado por alTurabi. Dada la formación en Derecho del líder del islamismo sudanés, al-Turabi apostaba por una islamización progresiva de la legislación como método ideal para provocar el cambio social hacia un Estado islámico, a diferencia de otros movimientos islamistas que creen en la educación del individuo como motor del cambio. Así pues, el nuevo régimen defiende la aplicación de la sharia -la diferencia con el régimen de Numeyri residía en que con las autoridades islamistas se elaboró un sistema jurídico islámico completo, no limitado a la represión de los castigos corporales y al código penal-, la promulgación de un nuevo código de familia acorde con el derecho islámico e inspirado en el modelo ideal de la sociedad medinesa (la primera comunidad islámica de los primeros años del islam) códigos de vestimenta para mujeres... Las nuevas autoridades, con el presidente militar Omar Hasan al-Bashir, y el intelectual civil Hasan al-Turabi, procedieron a islamizar las instituciones y el lenguaje político (no es casualidad que años después al-Turabi publicara un opúsculo titulado Terminología politica en el islam) ${ }^{25}$ : la shura (consulta) y el iymaa (consenso general) sustituyeron al concepto de "democracia”, es más, según las propias concepciones del islamismo sudanés la asamblea de la shura es la base organizativa de la democracia ${ }^{26}$.

También se promovió la islamización de la moral pública, directriz que se relaciona con el concepto mencionado anteriormente de hisba (la obligación de todo buen musulmán de contribuir a la creación de una sociedad islámica a través de la promoción de la virtud y la prevención el vicio, tarea que puede realizar a través de la palabra y la predicación con el ejemplo, o a través de la fuerza y la coerción). Para ello, el nuevo régimen creó un cuerpo de "guardianes de la moral”, la llamada "Policía popular" (también conocida como al-Murabitun).

\footnotetext{
24 Alain Chevalérias, Hassan Al-Tourabi, Islam, avenir du monde. Entretiens avec Alain Chevalérias, Saint-Amand-Montrond, JCLattès, 1997, p. 306.

25 Además, los movimientos islamistas en diferentes países arabo-islámicos han mostrado normalmente muchas reticencias a utilizar un lenguaje político "occidental" que en numerosas ocasiones se asimilaba a sistemas coloniales.

${ }^{26}$ Véase Hasan al-Turabi (wa-Ajarun), Hiwarat fi-l-islam, al-dimuqratiyya, al-dawla, al-garb, Beirut, Dar al-Yadid, 1995, p. 34.
} 
Asimismo, el nuevo régimen llevó a cabo la islamización de la educación, considerada como un pilar de la islamización de la sociedad: ignoró el sistema educativo previo al golpe de Estado islamista de 1989 visto como algo meramente occidental y ajeno a la identidad sudanesa, recuperó el sistema de las escuelas coránicas, impulsó nuevas universidades islámicas como la Universidad de El Corán y Ciencias Islámicas "para difundir las ciencias de la religión en Sudán y en otros países, especialmente en países africanos", tal y como aparece en el decreto de creación de dicha universidad ${ }^{27}$.

La "cuestión del sur", es decir la larga guerra civil sudanesa que había comenzado con el proceso mismo de independencia y que había pasado por diferentes fases, incluyendo una tregua de 10 años desde 1972 a 1983, no podía escapar a todo el proceso de islamización impuesto desde el triunfo golpista islamista. Así, la islamización de la guerra se produjo por medio de las Fuerzas de Defensa Popular, cuerpo paramilitar creado por el régimen islamista, por el que tenían que pasar obligatoriamente los jóvenes sudaneses (entre los 18 y 30 años) para recibir entrenamiento militar y adoctrinamiento religioso basado en el yihad. La declaración del yihad fue el segundo mecanismo que operó en la islamización de la guerra, declaración propiciada por las instituciones del islam oficial sudanés (Organismo de Ulemas de Sudán, la Academia de Derecho Islámico, Organismo de Ulemas de los Musulmanes, además de imanes de mezquitas, maestros de escuelas coránicas, maestros sufíes), que declararon el yihad contra los "apóstatas" (musulmanes que se habían rebelado contra el Estado) y contra los "paganos" (los no musulmanes), esto influyó en que la doctrina militar del ejército regular se fuera orientando poco a poco hacia el concepto islámico de yihad.

Por otro lado, en el marco del "proyecto civilizacional" teorizado por alTurabi antes del golpe de Estado de 1989, las nuevas autoridades pusieron en marcha una islamización de las relaciones exteriores según la cual las fronteras del país estarían abiertas, sin trabas, para árabes y musulmanes. Gracias a esta política, Sudán se convirtió en hogar y refugio de islamistas perseguidos en sus respectivos países (básicamente representantes de la oposición armada aunque también política), y para individuos que ya no tenían otro refugio porque la escena internacional estaba cambiando rápidamente (caída del muro, derrumbe de la Unión Soviética, surgimiento de una potencia única, la de EEUU, un nuevo "eje del mal" constituido por países islámicos díscolos... En ese contexto internacional cambiante, apenas esbozado aquí, personajes como el venezolano Ilich Ramírez Sánchez, conocido como Carlos el Chacal, miembro del Frente Popular para la Liberación de Palestina en la década de los 70, convertido al islam y con una relación turbulenta con varias causas árabes, y el saudí Osama

\footnotetext{
${ }^{27}$ Rafael Ortega Rodrigo, Evolución del islam político en Sudán: de los Hermanos Musulmanes al Congreso Nacional, Granada, Editorial de la Universidad de Granada, 2005, p. 287.
} 
Ben Laden encontraron refugio temporal en Jartum en la primera mitad de los noventa del siglo pasado así como miembros de la oposición armada islamista egipcia, palestina o libanesa. Esta política de puertas abiertas, enlaza con la otra dimensión del proyecto civilizacional de al-Turabi: la creación de una internacional islamista con sede en Jartum alternativa a la Organización Internacional de los Hermanos Musulmanes de Egipto.

\section{La Conferencia Popular Árabe e Islámica}

Realmente, la dimensión internacional del islamismo sudanés no surgió de la nada en 1991, es más tanto el islam como el islamismo han tenido desde su nacimiento una tendencia a la universalización de sus propuestas. En el caso que nos ocupa, podríamos remontarnos a las primeras experiencias europeas, tanto de al-Turabi como de otros dirigentes sudaneses, en los años sesenta del s. XX que se instalaron preferiblemente en Inglaterra o Francia para ampliar estudios universitarios y que participaron activamente en la vida estudiantil de universidades europeas. Además, fue una época de exilio europeo de dirigentes de otros movimientos islamistas egipcios, sirios e iraquíes. Eso contribuyó a la creación de unos primeros vínculos transfronterizos que servirían para la posterior puesta en marcha de la internacional islamista sudanesa. Y como la historia del islamismo sudanés también contempló episodios de represión con los regímenes dictatoriales de Ibrahim Abbud (1958-1964) y Yaafar Numeyri (1969-1985), ello provocó el exilio de dirigentes lo que contribuyó también a establecer contactos con otros movimientos en el extranjero.

Según refiere el propio al-Turabi, en la segunda mitad de los 80 el Frente Islámico Nacional estableció las bases teóricas para la creación de "una conferencia mundial del movimiento islamista que reúna a todos sus múltiples elementos" ${ }^{28}$, pero no fue hasta 1991 cuando la idea se plasmó en la práctica, propiciado por el fracaso de los organismos internacionales existentes (ONU, Liga del Mundo Islámico, Internacional de los Hermanos Musulmanes, Organización de la Conferencia Islámica, Liga Árabe...) que no pudieron evitar la guerra del Golfo posterior a la invasión iraquí de Kuwait del 2 de agosto de 1990. Un foro internacional de debate, de intercambio de experiencias, presidido por al-Turabi, en el que se dieran cita representantes de movimientos populares árabes e islámicos, intelectuales, políticos, líderes oficiales de países islámicos, líderes revolucionarios izquierdistas y laicos, delegaciones de comunidades islámicas europeas, sudamericanas, líderes religiosos musulmanes suníes y shiíes, católicos... El foro se reunió en Jartum con dos objetivos visibles: apoyar al régimen islamista en unos momentos en

${ }^{28}$ Hasan al-Turabi, al-Haraka al-islamiyya fi-l-Sudan. Al-Tatawwur, al-kasb, al-minhay, Jartum: s.e., 1989, p. 279.

Araucaria. Revista Iberoamericana de Filosofia, Política, Humanidades y Relaciones Internacionales, año $21, \mathrm{n}^{\circ} 41$ Primer semestre de 2019. Pp. 439-464. ISSN 1575-6823 e-ISSN 2340-2199 doi: 10.12795/araucaria.2019.i41.21 
los que sufría el boicot internacional y debatir cuestiones que afectaban a la comunidad árabe e islámica. Las actas de los tres congresos realizados recogen los temas analizados ${ }^{29}$ : la intifada palestina (de hecho en el primer congreso de la CPAI participó el propio Yaser Arafat), la guerra contra Iraq lanzada por Estados Unidos, la lucha por la independencia de Eritrea y la participación islamista en la misma, las injerencias extranjeras en Somalia, la cuestión afgana y las mediaciones de al-Turabi, la represión india contra los musulmanes de Cachemira, el diálogo de civilizaciones Norte-Sur, el apoyo a las organizaciones de predicación islámica en Asia y África, la situación en el sur de Sudán en plena guerra civil. Estos fueron algunos de los temas más importantes abordados por los 500 congresistas que se dieron cita en el congreso fundacional de la CPAI celebrado en Jartum del 25 al 28 de abril de 1991. Los foros del segundo y tercer congresos, celebrados en diciembre de 1993 y marzo de 1995, abordarían estos y otros temas que se fueron añadiendo a las agendas árabes e islámicas: Argelia, Yemen, Afganistán, Palestina, Bosnia-Herzegovina, Somalia, Myanmar, Cachemira, Sudáfrica, América Latina, el apoyo a la experiencia islamista sudanesa, Chechenia, el papel de la mujer, los jóvenes, el voluntariado y la predicación.

Ahora bien, desde otras latitudes, especialmente desde Estados Unidos y desde países árabes vecinos, la CPAI era vista como un foro de coordinación de movimientos radicales y del terrorismo internacional ${ }^{30}$.

Las presiones internacionales sobre el régimen sudanés para que pusiera fin a ese foro si quería volver a la sociedad internacional y ver anuladas las sanciones impuestas por la Casa Blanca, el aislacionismo, las política internas (al-Turabi comenzó a inclinarse más por participar en la política interior y no tanto en la dimensión internacional) fueron debilitando a la CPAI y acabaron con su disolución.

Y cuanto más se dedicaba al-Turabi a la política interna sudanesa más fuertes se fueron haciendo las tensiones en la jefatura bicéfala al-Turabi/alBashir. Una lucha de poder que acabó perdiendo al-Turabi, a pesar de sus intentos de reducir las competencias del presidente de la República en el Parlamento que desde 1996 presidía el sheyj. El deterioro de las relaciones entre ambos líderes produjo también un desgaste en el seno del islamismo sudanés que desde entonces vivió importantes escisiones y rupturas, una progresiva marginación de al-Turabi hasta su fallecimiento en marzo de 2016, y una erosión del "proyecto civilizacional" islámico teorizado por al-

\footnotetext{
${ }^{29}$ La documentación generada por la CPAI disponible es: Comunicado político, Carta de la CPAI, Estatutos de la CPAI, Recomendaciones y resoluciones (Primer Congreso), Recomendaciones finales, Discurso del Secretario General (Segundo Congreso), Comunicado de Posturas y recomendaciones, Informe del Secretariado General (Tercer Congreso)

${ }^{30}$ Véase al respecto el estudio de J. Millard Burr y Robert O. Collins, Revolutionary Sudan. Hasan al-Turabi and the Islamist State, 1989-2000, Brill, Leiden-Boston, 2003.
} 
Turabi que se intentó poner en pie en los primeros años del régimen islamista sudanés.

Los acuerdos de paz de 2005 y el posterior referéndum de independencia de las provincias meridionales en 2011 condujeron a la creación de la República de Sudán del Sur el 9 de julio de ese mismo año. Mientras, el proyecto civilizacional del islamismo sudanés había entrado en plena decadencia aunque todavía había voces que consideraban que tras la separación de las provincias del sur de mayoría cristiana y animista, podrían crear en el norte un auténtico Estado islámico, perfectamente cohesionado ya que la población no musulmana emigraría al nuevo Estado del sur.

Además, las propias autoridades islamistas sudanesas están recibiendo las críticas de otro actor político, el salafismo. Es como si el espacio social que hasta principios del siglo XXI había ocupado el islamismo del FIN y del sheyj al-Turabi lo estuviera ocupando ahora, tras el fracaso del "proyecto civilizacional", el salafismo en tensión con el régimen ${ }^{31}$ y con las cofradías sufíes (el sufismo considera la doctrina salafí como "corrompida" y el salafismo califica a los sufíes como "kuffar", infieles).

\section{Otra visión del islam y otro activismo: Mahmud Muhammad Taha}

El islam en Sudán generó igualmente otras propuestas teóricas y aplicaciones prácticas a lo largo del siglo XX, lo que demuestra y pone de relieve la pluralidad y diversidad existente en el seno del islam, del islamismo y de Sudán. Nos referimos a la obra y al activismo del pensador y político Mahmud Muhammad Taha (1909-1985) ${ }^{32}$, autor de una importante obra intelectual que debe revisarse y de unas propuestas políticas que introdujeron nuevas dinámicas en el panorama sudanés. Tanto su pensamiento como su activismo le llevaron a enfrentarse a los poderes establecidos en las décadas de los 70 y 80, así como a las injerencias extranjeras, especialmente saudíes, y todo ello desembocó en un juicio sumarial en el que fue acusado de apostasía y condenado a pena de muerte. Taha fue ejecutado, públicamente, en enero de 1985. Esa actuación del régimen de Numeyri tuvo repercusiones internacionales (países occidentales que hasta ese momento apoyaban el arbitrario régimen sudanés le volvieron la espalda) y locales: fue el detonante de un levantamiento popular que acabó con el presidente Numeyri. Taha comenzó su vida pública escribiendo artículos en los que criticaba el colonialismo británico y los partidos tradicionales sudaneses

31 Véase Noah Salomon, "The Salafi Critique of Islamism. Doctrine, Difference and the Problem of Islamic Political Action in Contemporary Sudan", en MEIJER, Roel, ed.: Global Salafism. Islam's New Religious Movement, London, Hurst \& Company, 2009, pp. 143-168.

${ }^{32}$ La biografía, las obras y material documental sobre Taha están disponibles en la página web www.alfikra.org

Araucaria. Revista Iberoamericana de Filosofia, Politica, Humanidades y Relaciones Internacionales, año $21, \mathrm{n}^{\circ} 41$ Primer semestre de 2019. Pp. 439-464. ISSN 1575-6823 e-ISSN 2340-2199 doi: 10.12795/araucaria.2019.i41.21 
(esos grandes partidos emanados de las principales tariqas sufíes). En 1945 fundó el Partido Republicano que defendía la independencia de Sudán y denunciaba la presencia británica, lo que le supuso su primer ingreso en la cárcel en 1946. En 1951 regresó al activismo político y comenzó a publicar sus ensayos, por ejemplo Este es mi camino, Fundamentos de la constitución en Sudán-en el que abogaba por la creación de una república presidencialista, federal, democrática y socialista-, El islam que incluía las bases del renacimiento del islam defendido por el partido y le granjeó la enemistad del islamismo sudanés, representado en esos momentos, 1960, por los Hermanos Musulmanes. Sus ideas sobre el renacimiento del islam -especialmente las contenidas en su ensayo El primer mensaje del islam no encaja con el humanismo del siglo $X X-$ y su actitud contraria a la modificación de la Constitución, defendida por los Hermanos Musulmanes para ilegalizar al Partido Comunista Sudanés, provocaron un primer juicio y una primera acusación de apostasía en 1968. Pero el golpe de Estado del coronel Yaafar Numeyri (1969) y la posterior ilegalización de todos los partidos, cambió el escenario sudanés. El grupo de Taha pasó a denominarse Hermanos Republicanos, grupo que comenzó a denunciar la creciente influencia saudí en el país y algunos excesos del nuevo régimen sudanés, entre ellos la promulgación de las leyes de septiembre de 1983, presentadas como un corpus jurídico basado en la legislación islámica, en la sharia. Sin embargo, para Taha suponían una deformación del islam, contravenían la legislación islámica y la religión, y eran, sobre todo, leyes represivas que amenazaban la unidad del país agravando las desigualdades entre musulmanes y cristianos (la República de Sudán contaba en la década de los 80 del pasado siglo con una importante minoría cristiana, el 7,8\% de la población, y animista, el 19,3\%). Estas ideas las reflejó Taha en su ensayo Esto... o el diluvio. Los Hermanos Republicanos exigieron la abolición de las leyes de septiembre y ese nuevo enfrentamiento con el régimen de Numeyri resultó fatal para Taha y su grupo. El líder de los Hermanos Republicanos fue detenido de nuevo, juzgado por apostasía en virtud precisamente de esas nuevas Leyes de septiembre, encontrado culpable y ajusticiado el 18 de enero de 1985. "La ejecución de Mahmud Taha, que había provocado el rechazo de la clase intelectual sudanesa, también contribuyó al deterioro de las relaciones con otros países. Realmente, el ahorcamiento de un pensador casi octogenario calificado por la prensa de medio mundo como el "Gandhi de Sudán" o el "Gandhi de África" por su apuesta por la paz, empeoró la imagen del régimen de Numeyri de quien se esperaba la conmutación de la pena tras las presiones tanto de Egipto como de Estados Unidos, Gran Bretaña y de Amnistía Internacional, y le convirtió en blanco de duras críticas y reproches, además de despertar las dudas sobre la justicia islámica, o la posibilidad de una comprensión moderna del islam en los países islámicos, debida a la 
asimilación de la pena de muerte con la sharia" ${ }^{33}$. El proyecto reformista de Mahmud Muhammad Taha fue recogido por algunos de sus discípulos entre los que destaca Abdullahi Ahmed an-Na'im, quien tuvo que abandonar Sudán tras la ejecución de Taha y actualmente es profesor de Derecho en la Emory University de Atlanta.

El islam y el islamismo sudanés han hecho importantes aportaciones al continente africano, al mundo árabe y a Occidente en general. Ya hemos visto las proyecciones internacionales del islamismo sudanés, especialmente de la mano del sheyj Hasan al-Turabi (las relaciones con los países del entorno, la política de fronteras abiertas para la oposición islamista de países árabes e islámicos, y su proyecto de internacional, la Conferencia Popular Árabe Islámica de Jartum). Pero también la rama sudanesa de la asociación salafí Ansar al-Sunna al-Muhammadiyya (creada en Omdurmán en 1939) tuvo una dimensión internacional, ya que uno de sus fundadores, el sheyj Ahmad Hasun, viajó a EEUU para dirigir el grupo y divulgar sus enseñanzas. Tales enseñanzas llegaron hasta Malik al-Shabbaz, el nombre que adoptó tras su conversión al islam el activista afroamericano Malcom X (1925-1965). Maestros, shuyuj y estudiantes sudaneses en Estados Unidos contribuyeron, si no a su conversión, sí a la educación islámica de Malcom $\mathrm{X}^{34}$. Incluso el activista afroamericano se inspiró en la figura de al-Mahdi del siglo XIX (que, recordemos, fue reivindicada por diferentes presidentes sudaneses) y en su movimiento ya que lo veía como un enfrentamiento entre "negros y blancos".

\section{Conclusiones}

El islam sudanés, y la experiencia histórica sudanesa, y sus aportaciones a los diferentes ámbitos del islam, desmontan las teorías muy extendidas en

\footnotetext{
${ }^{33}$ Rafael Ortega Rodrigo, Evolución del islam politico en Sudán: de los Hermanos Musulmanes al Congreso Nacional, Granada, Editorial Universidad de Granada, 2005, p. 213. Para un análisis del pensamiento reformista de Taha, pueden consultarse Ghassan Finianos, Islamistes, apologistes et libres penseurs, Pessac, Presses Universitaires de Bordeaux, 2002, pp. 177-215; y Rafael Ortega Rodrigo, El movimiento islamista sudanés. Discursos, estrategias y transformaciones. Alcalá la Real: Alcalá Grupo Editorial, 2010, pp. 147-159.

34 Emily O' Dell, "Following in the Footsteps of Malcom X" en https:/www.huffingtonpost.com/ emily-odell/following-in-the-footstep 3 b 6434534.html Malcom X visitó Sudán en 1959, en el marco de un programa de visitas por países africanos y de Oriente Medio. Según la investigadora Emily O' Dell sus continuos contactos con estudiantes sudaneses, y con ulemas de Sudán, Líbano y EEUU contribuyeron a formar sus ideas sobre el proselitismo islámico, sobre religión y etnia. Durante su visita a Sudán, en calidad de portavoz del grupo Ummat al-islam, fue huésped del ulema sudanés Malik Badri. Por otro lado, Malcom X tuvo una relación de amistad con un estudiante sudanés de la universidad de Dartmouth llamado Ahmad Uzman quien, al parecer, corrigió algunas de las ideas erróneas sobre el islam que tenía Malcom X (por ejemplo sobre la esclavitud). En 1964, Malcom X se encontró con su "maestro" sudanés, el sheyj Ahmad Hasun durante la peregrinación a La Meca y se lo llevó a Harlem como muftí de la fundación Yamaat al-Islam.
} 
círculos musulmanes que tienen una visión racial de la fe y consideran el islam negro como algo periférico, ignorando que "África fue el segundo hogar de los primeros conversos"35. La fuerte presencia sufí, la islamización y el proselitismo hacia países vecinos del África negra, el pensamiento y la obra del líder islamista Hasan al-Turabi; la primera experiencia de un gobierno islamista; el islam reformista de Mahmud Muhammad Taha; el islam revolucionario; la presencia de maestros y ulemas sudaneses en Estados Unidos. Todo ello, a pesar de ser un país que oscila entre el mundo árabe y el mundo negro subsahariano, nos habla de la gran capacidad de adaptación y movilización del islam en contextos africanos y de su papel como elemento legitimador para grandes sectores de la población, partidos o regímenes (el ejemplo del presidente Numeyri es notorio, aunque no sea una novedad en el mundo árabe, y llegaría bastante más lejos al proclamarse imán y emir de los creyentes).

Así, el islam sudanés, en todas sus vertientes, la sufí, la reformista, la islamista, traspasó las fronteras nacionales y, en círculos, tal y como había teorizado años antes el sheyj Hasan al-Turabi, fue ampliando su radio de influencia al mundo árabe, africano e islámico, tanto en países musulmanes como en aquellos en los que el islam se vive como apuesta minoritaria, desde los pueblos del sur de un Sudán todavía unificado, hasta las calles de Boston o Nueva York acompañando al hajj Malik El Shabbaz, antes conocido como Malcom X.

${ }^{35}$ Tal y como señala Muhammad Nizami en "No hubo ninguna contribución negra al islam". En https://redislamicainclusiva.wordpress.com/2017/11/05/no-hubo-ninguna-contribucion-negra-alislam/ 


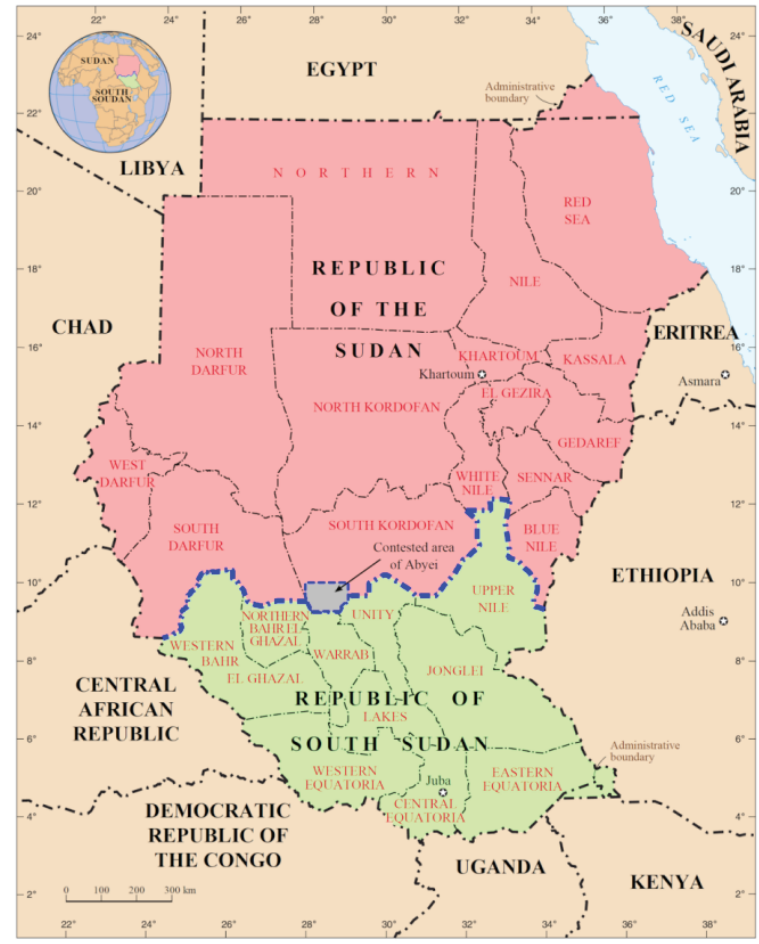

Fuente: Naciones Unidas 


\section{Referencias bibliográficas:}

Collins, Robert O., A History of Modern Sudan, New York, Cambridge University Press, 2008.

Cuoq, Joseph M., Les musulmans en Afrique, Paris, Maisonneuve-Larose, 1975.

Chevalerias, Alain, Hassan Al-Tourabi, Islam, avenir du monde. Entretiens avec Alain Chevalérias, Saint-Amand-Montrond, JCLattès, 1997.

Finianos, Ghassan, Islamistes, apologistes et libres penseurs, Pessac, Presses Universitaires de Bordeaux, 2002.

Grandin, Nicole, "El noreste y el este de África", [en Alexandre Popovic y Gilles Veisntein, eds.: Las sendas de Allah. Las cofradias musulmanas desde sus orígenes hasta la actualidad, Barcelona, Bellaterra, 1997], pp. 527-543.

Hodgkin, Thomas, "Mahdismo, mesianismo y marxismo en el continente africano", [en El empuje del islam, África Internacional, n ${ }^{\circ}$ 7, 1988

Holt, P. M., “al-Mahdiyya”, Encyclopédie de 1'Islam, 2a ed., vol V, p. 1238.

Lavergne, Marc, ed. : Le Soudan contemporain. De l'invasion turco-égyptienne à la rèbellion africaine (1821-1989), Paris-Amman: Karthala-Cermoc, 1989.

Makki, Hasan, al-Haraka al-islamiyya fi-l-Sudan (1969-1985). Tariju-ha wajitabu-ha l-siyasi (El movimiento islamista en Sudán 1969-1985. Historia y discurso político), Jartum, al-Dar al-Sudaniyya li-l-Kutub, 1999.

---------- Harakat al-Ijwan al-Muslimin fi-l-Sudan 1944-1969 (El movimiento de los Hermanos Musulmanes en Sudán, 1944-1969), Kuwait, Dar alQalam li-1-Nashr wa-1-Tawzii, 1986.

Meijer, Roel, ed.: Global Salafism. Islam's New Religious Movement, London, Hurst \& Company, 2009.

Millard Burr, J. y Collins, Robert O., Revolutionary Sudan. Hasan al-Turabi and the Islamist State, 1989-2000, Brill, Leiden-Boston, 2003.

Mosely Lesch, Ann, The Sudan. Contested ational Identities, BloomingtonOxford, Indiana University Press y James Currey Ltd., 1998.

Mulla Huech, Bahige, Diccionario del Sagrado Corán, Barcelona, Consestruc, 2013.

Ortega Rodrigo, Rafael, El movimiento islamista sudanés. Discursos, estrategias y transformaciones, Alcalá la Real, Alcalá Grupo Editorial, 2010.

Evolución del islam político en Sudán: de los Hermanos Musulmanes al Congreso Nacional, Granada, Editorial de la Universidad de Granada, 2005 . 
El islam político en Sudán. Una propuesta fallida de internacional islamista, Granada: Editorial Universidad de Granada, 2004.

Popovic, Alexandre y veisntein, Gilles, eds.: Las sendas de Allah. Las cofradías musulmanas desde sus origenes hasta la actualidad, Barcelona, Bellaterra, 1997.

Prunier, Gérard, "Les Fréres musulmans au Soudan: un islamisme tacticien" [en Marc Lavergne, ed. : Le Soudan contemporain. De l'invasion turcoégyptienne à la rèbellion africaine (1821-1989), Paris-Amman: KarthalaCermoc, 1989], pp. 359-380.

Said Al-Qaddal, Muhamad, al-Islam wa-l-siyasa fi-l-Sudan 1651-1985 (Islam y política en Sudán. 1651-1985), Beirut, Dar al-Yil, 1992

Salim Al-Hasan, Idris, al-Din fi-l-muytamaa al-sudani. Numayri wa-l-turuq al-sufiyya (La religión en la sociedad sudanesa. Numeyri y las cofradías sufíes), El Cairo: Markaz al-Dirasat al-Sudaniyya, 2002.

Salomon, Noah, "The Salafi Critique of Islamism. Doctrine, Difference and the Problem of Islamic Political Action in Contemporary Sudan", en MEIJER, Roel, ed.: Global Salafism. Islam's New Religious Movement, London, Hurst \& Company, 2009, pp. 143-168

Al-Turabi, Hasan, al-Haraka al-islamiyya fi-l-Sudan. Al-Tatawwur, al-kasb, alminhay (El movimiento islamista en Sudán. Evolución, logros y método), Jartum: s.e., 1989.

- Risalat al-Muutamar al-Thani (Epístola del Segundo Congreso), Jartum, al-Muhammadiyya, s.d.,

- Hiwarat fi-l-islam, al-dimuqratiyya, al-dawla, al-garb (Diálogos sobre el islam, la democracia, el Estado y Occidente), Beirut, Dar alYadid, 1995.

\section{Webgrafía}

Muhammad Nizami, "No hubo ninguna contribución negra al islam". En https:// redislamicainclusiva.wordpress.com/2017/11/05/no-hubo-ningunacontribucion-negra-al-islam/

Emily O' Dell, "Following in the Footsteps of Malcom X" en: https://www. huffingtonpost.com/emily-odell/following-in-the-footstep_3_b_6434534. html

Ahmad al-Bardini, "Awwal hizb sufi fi-l-Sudan... Hal intaha zaman aldarawish?” (Primer partido sufí en Sudán... ¿Ha concluido el tiempo de los derviches?), en https://raseef22.com

https://bit.ly/2Rvr61X 
«Munazzama al-Daawa al-Islamiyya» (Organización de Predicación Islámica) en www.aljazeera.net

https://bit.ly/2NgbZGf

www.alfikra.org (Vida y obra de Mahmud Muhammad Taha) 